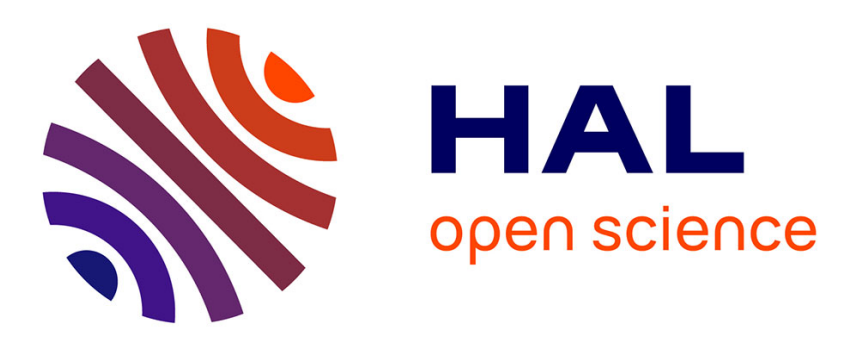

\title{
Hydrothermal conversion of glucose in multiscale batch processes. Analysis of the gas, liquid and solid residues
}

\author{
Qian Michelle Yu-Wu, Elsa Weiss-Hortala, Radu Barna
}

\section{To cite this version:}

Qian Michelle Yu-Wu, Elsa Weiss-Hortala, Radu Barna. Hydrothermal conversion of glucose in multiscale batch processes. Analysis of the gas, liquid and solid residues. Journal of Supercritical Fluids, 2013, 79 (SI), pp.76-83. 10.1016/j.supflu.2013.03.003 . hal-01688102

\section{HAL Id: hal-01688102 https://hal.science/hal-01688102}

Submitted on 4 May 2018

HAL is a multi-disciplinary open access archive for the deposit and dissemination of scientific research documents, whether they are published or not. The documents may come from teaching and research institutions in France or abroad, or from public or private research centers.
L'archive ouverte pluridisciplinaire HAL, est destinée au dépôt et à la diffusion de documents scientifiques de niveau recherche, publiés ou non, émanant des établissements d'enseignement et de recherche français ou étrangers, des laboratoires publics ou privés. 


\title{
Hydrothermal conversion of glucose in multiscale batch processes. Analysis of the gas, liquid and solid residues
}

\author{
Qian Michelle Yu-Wu, Elsa Weiss-Hortala*, Radu Barna \\ Université de Toulouse, Mines Albi, CNRS UMR 5302, Centre RAPSODEE, Campus Jarlard, F-81013 Albi Cedex 09, France
}

\section{A B S T R A C T}

Hydrothermal conversion is an interesting process to transform (very) humid biomass into high energy vectors or valuable products in the liquid or solid state. In the supercritical domain, water becomes a solvent for organics as well as a reactant, and thus the cellulosic content is effectively hydrolyzed into glucose, largely considered as its model molecule.

The kinetics of glucose decomposition during the heating step in the batch reactor were investigated through the analysis of glucose concentration. Glucose reacts totally before reaching the supercritical point of water. Among the operating parameters that influence supercritical water gasification, this paper presents only the effect of reaction temperature through gas composition, liquid carbon content and structure of the solid. Glucose gasification in a batch process ( $5 \mathrm{wt} \%$ glucose, $0.5 \mathrm{wt} \%$ catalyst, $600{ }^{\circ} \mathrm{C}$, $25 \mathrm{MPa}, 60 \mathrm{~min}$ ) produced $1.5 \mathrm{~mol}$ of hydrogen per mol of glucose. The gas has energetic properties $\left(\mathrm{H}_{2}\right.$, $\mathrm{CH}_{4}, \mathrm{C}_{2} \mathrm{H}_{6}$ ) while the liquid contains substances that could be used as platform molecules (5-HMF). The solid phase is composed of carbon (almost pure) in two distinct phases: spherical nanoparticles and an amorphous phase.

Glucose

Supercritical water

Characterization

Batch reactor

Hydrogen

\section{Introduction}

The accelerated demand and processing of raw materials and fossil energies is correlated to the observed depletion of resources and has global harmful effects: climate change etc. New technologies should be designed to operate more efficiently with raw materials and to reduce the impact of residues and waste. Sustainability is one of the most important challenges for industrial processes. One of the ways to achieve it is the development of an ecological economy, based on the circular structure of mass and energy flow.

Among the renewable energy and material sources, biomass has a central position. According to the EU definition, biomass represents the biodegradable fraction of products, waste and residues from biological origin as well as of industrial and municipal waste [1]. Biomass is mainly composed of $\mathrm{C}, \mathrm{H}$ and $\mathrm{O}$, containing other elements like N, P, S, etc. The huge variety of organic substances, associated more or less with metals, salts, water, etc. has allowed the implementation of a large number of traditional industrial processes converting specific classes of biomass into valuable products.

* Corresponding author at: RAPSODEE Center Ecole des Mines d'Albi-Carmaux, Route de Teillet, Campus Jarlard, F-81013 Albi Cedex 9, France. Tel.: +33 563493145; fax: +33 563493243 .

E-mail address: elsa.weiss@mines-albi.fr (E. Weiss-Hortala).
Biomass (wood, organic residues, etc.) could be used for heating and energy production and thus competes with fossil fuels.

The biorefinery approach develops integrated complex transformation processes of biomass into compounds for organic synthesis (platform molecules or building blocks), bioliquids and biofuels [2]. Among these transformation processes, hydrothermal conversion of biomass in supercritical or near critical conditions allows transformation of very humid biomass into valuable gaseous, liquid and solid products, characterized by high energetic (hydrogen, low hydrocarbons) and/or chemical potential [3]. These processes are still under research and development at laboratory and pilot scale [4]. Water becomes a particular "partner" of the organic species in the system when it is brought near to its critical point: $T_{C}=374^{\circ} \mathrm{C}$ and $P_{c}=22.1 \mathrm{MPa}$ [5]. During the transition of the system from normal to supercritical conditions (where the system is monophasic [6]), the physico-chemical properties of water change continuously [7]. The change is dramatic in the region close to the critical point [5]. The change observed in water properties (dielectric constant, density, ionic product, caloric capacity, etc.) on the path from normal to the supercritical domain [8-10] has important consequences on its dissolving properties $[5,10]$ and reactivity. In the subcritical domain, water favors heterolitic/ionic mechanisms [5,11], like catalytic hydrolysis, while in the supercritical domain radical reactions [12] are favored. Sub/supercritical water is an interesting reactant because it optimizes the reaction rate by a concentration effect and higher temperature, diffusivity and collision yield. In these conditions, biomass is converted into various gaseous, liquid and solid 
products. Schematically, the relative proportion of the three main elements $\mathrm{C}_{x} \mathrm{H}_{y} \mathrm{O}_{z}$ can represent the organic part of biomass. In fact, biomass composition is very diverse: cellulose, lignin, hemicelluloses, fats, proteins, carbohydrates etc. The reactivity of these different classes in sub/supercritical water is different, e.g., cellulose $\left(\mathrm{C}_{6} \mathrm{H}_{10} \mathrm{O}_{5}\right)_{n}$, the main component of the lignocellulosic biomass, hydrolyses quantitatively to glucose before further conversion.

Glucose $\left(\mathrm{C}_{6} \mathrm{H}_{12} \mathrm{O}_{6}\right)$ is widely considered as one of the simplest model molecules of cellulosic biomass, and its conversion in supercritical water was largely investigated in batch and continuous operating reactors [12-19]. The main products of glucose SCW conversion identified in the liquid phase are: furfurals (like 5-hydroxy methyl furfural, $5 \mathrm{HMF}$ ), carboxylic acids (formic, acetic, levulinic, etc.), aldehydes (formic, acetic, etc.), etc. [16,20-26], and in the gas phase are: $\mathrm{H}_{2}$ and $\mathrm{CO}_{2}$ but also $\mathrm{CO}$ and different light hydrocarbons (methane, ethane, propane, etc.) [14]. High temperature and alkaline or metallic catalysts $[13,27,28]$ favor gas production and its hydrogen content, while high glucose concentration and/or pressure limits gasification yield [16-18,23,25,26]. In steady state continuous processes the heating rate of the biomass (e.g., glucose) is performed very rapidly, and generally it is accepted that non-converted biomass reacts in the supercritical phase. Supercritical water gasification of glucose has been largely investigated, and different degradation mechanisms have been proposed. Literature data indicate that glucose reacts at temperatures above the critical point [29]. However glucose reactivity during the heating step has not yet been studied. The assumption of "instantaneous" (flash) heating of the biomass is even less realistic when operating batch reactors with limited (known) heating rate. During autoclave heating, properties of water and the composition of the system are changing, which plays an important role in the relative yield of the different possible reactions (successive, parallel, concurrent, etc.) between the components of the system, i.e., water and the more or less converted organic reactant.

The first part of our paper investigates glucose degradation during controlled heating of the $500 \mathrm{~mL}$ stirred batch autoclave. The equipment allows sampling of small aliquots of liquid, which is performed after every $10^{\circ} \mathrm{C}$ rise in temperature during heating. We demonstrated previously that the composition of a glycerol solution arriving in supercritical conditions have been strongly affected by the heating step [30] and seems to depend on the "history" of its operating parameters (heating rate, contact time, initial filling ratio, etc.). Therefore we studied the glucose degradation rate during heating. Then it was decided to investigate the influence of different operating parameters on batch supercritical conversion of glucose solution: the initial liquid ratio and composition, heating time and/or rate, residence time in supercritical conditions (controlled temperature and self-generated pressure in the reactor), etc. Special attention was given to the optimal gasification conditions. The experiments have been performed at two autoclave scales, 5 and $500 \mathrm{~mL}$, and the gas produced, liquid and solid phases were characterized. Table 1 summarizes the ranges of the operating parameters explored by our project, and detailed results are presented by $\mathrm{Yu}-\mathrm{Wu}$ [31]. According to our experience, the operating parameter with the greatest influence on gasification yield is the steady temperature of the process. Thereafter we will discuss our main results in this respect.

\section{Materials and methods}

\subsection{Reagents and reactors}

Experiments were carried out in two kinds of batch reactors of 5 and $500 \mathrm{~mL}$, filled with accurate predetermined liquid mass (precision $0.1 \mathrm{mg}$ ). In both cases, the reaction temperature was
Table 1

Summary of all the experiments done by $\mathrm{Yu}-\mathrm{Wu}$ [31] in $5 \mathrm{~mL}$ batch reactors.

\begin{tabular}{|c|c|c|}
\hline Investigated parameter & $\begin{array}{l}\text { Investigated } \\
\text { range }\end{array}$ & Constant maintained parameters \\
\hline$T$ & $400-600^{\circ} \mathrm{C}$ & $\begin{array}{l}25 \mathrm{MPa}, 60 \mathrm{~min} \text {, [glucose }]=5 \mathrm{wt} \%, \\
{\left[\mathrm{~K}_{2} \mathrm{CO}_{3}\right]=1 \mathrm{wt} \%}\end{array}$ \\
\hline$t$ & $5-120 \mathrm{~min}$ & $\begin{array}{l}\left.600{ }^{\circ} \mathrm{C}, 25 \mathrm{MPa}, \text { [glucose }\right]=5 \mathrm{wt} \% \\
{\left[\mathrm{~K}_{2} \mathrm{CO}_{3}\right]=1 \mathrm{wt} \%}\end{array}$ \\
\hline [glucose] & $5-20 w t \%$ & $\begin{array}{l}600^{\circ} \mathrm{C}, 25 \mathrm{MPa}, 60 \mathrm{~min} \\
{\left[\mathrm{~K}_{2} \mathrm{CO}_{3}\right]=1 \mathrm{wt} \%}\end{array}$ \\
\hline$\left[\mathrm{K}_{2} \mathrm{CO}_{3}\right]$ & $0-2 \mathrm{wt} \%$ & $\begin{array}{l}600^{\circ} \mathrm{C}, 25 \mathrm{MPa}, 60 \mathrm{~min}, \\
\text { [glucose] = } 5 \mathrm{wt} \%\end{array}$ \\
\hline$P$ & $20-28 \mathrm{MPa}$ & $\begin{array}{l}\left.600^{\circ} \mathrm{C}, 60 \mathrm{~min} \text {, [glucose }\right]=5 \mathrm{wt} \% \\
{\left[\mathrm{~K}_{2} \mathrm{CO}_{3}\right]=1 \mathrm{wt} \%}\end{array}$ \\
\hline
\end{tabular}

reached after controlled heating, and the autoclave pressure was auto-generated.

\subsubsection{Stirred batch reactor, $500 \mathrm{~mL}$}

The stirred batch autoclave $(500 \mathrm{~mL})$ was used to study the effect of the heating process on the composition of a pure glucose solution. This reactor is composed of a reaction shell in Inconel 718 (6.5 cm diameter) and an outer shell in stainless steel 316. The electric resistance confined in the stainless steel shell provides heating (maximum rate $20^{\circ} \mathrm{C} \mathrm{min}^{-1}$ ), and cooling is achieved by injecting cold air in the outer shell (rate $10^{\circ} \mathrm{C} \mathrm{min}^{-1}$ ). The installation was instrumented to control stirring rate, temperature (bottom and top) and to record inner pressure. The reactor comprises a valve connected with a long tube, allowing liquid phase sampling from the bottom zone of the autoclave. Small aliquots of liquid (less than $1 \mathrm{~mL}$ ) have been collected and analyzed every $10^{\circ} \mathrm{C}$ during system heating, between 20 and $250{ }^{\circ} \mathrm{C}$.

\subsubsection{Unstirred mini autoclaves, $5 \mathrm{~mL}$}

The mini-autoclaves $(5 \mathrm{~mL})$ are not instrumented. Made of 316 stainless steel, their inner and outer diameters are 8.5 and $31.4 \mathrm{~mm}$, respectively. A copper joint was used in order to improve the watertight quality. The volume being low, each experiment was carried out with 5 mini-autoclaves running simultaneously, and average results are presented. The mass of initial solution varied from $0.362 \mathrm{~g}\left(T=600^{\circ} \mathrm{C}\right)$ to $0.847 \mathrm{~g}\left(T=400^{\circ} \mathrm{C}\right)$.

The process was conducted by placing the 5 mini-autoclaves in a muffle oven (Nabertherm L5/11/P320) preheated to target temperature. After autoclaves introduction, a heating time of $10 \mathrm{~min}$ was necessary in the oven to reach the target temperature. At the end of the set reaction time, autoclaves were cooled down to room temperature $\left(25 \pm 2{ }^{\circ} \mathrm{C}\right)$ for $26 \mathrm{~min}$. Estimated heating and cooling rates were about $50{ }^{\circ} \mathrm{C} \mathrm{min}^{-1}$ and respectively $20^{\circ} \mathrm{C} \mathrm{min}^{-1}$.

The cooled autoclaves were opened in a special sampling system designed to collect separately the produced gas. The overpressure obtained in the calibrated device by opening the autoclave allows the determination of the amount of gas produced in each autoclave (system volume is $16.7 \mathrm{~mL}$ ).

\subsubsection{Reagents}

The processed solutions were prepared with pure water, glucose (water free, Prolabo) at $5 \mathrm{wt} \%$, and an alkaline catalyst, $\mathrm{K}_{2} \mathrm{CO}_{3}$ (99.0-100.0\%, Prolabo) at 0.5 wt\%.

\subsection{Characterization of gaseous, liquid and solid residues}

\subsubsection{Gaseous residue}

The gas phase $\left(\mathrm{H}_{2}, \mathrm{CO}_{2}, \mathrm{CO}, \mathrm{CH}_{4}\right.$, etc. $)$ was analyzed by a gas chromatograph (Agilent GC-3000 with 4 columns and 4 TCD detectors). Depending on the column, the carrier gases used were argon or helium. The average compositions of the 5 mini-autoclaves 


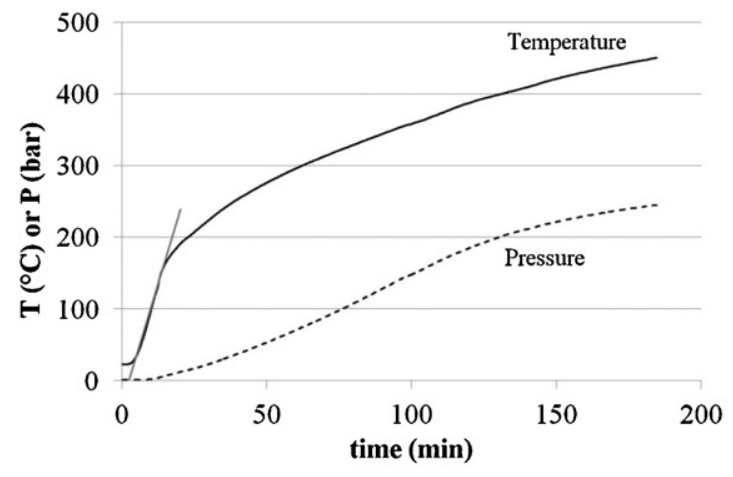

Fig. 1. Temperature and pressure profiles as function of time obtained experimentally during the heating of a glucose solution in the $500 \mathrm{~mL}$ batch reactor.

processed in parallel are presented. Carbon and hydrogen conversion $\mathrm{X}$ from glucose to gas $\left(\mathrm{H}_{2}, \mathrm{CO}_{2}, \mathrm{CO}, \mathrm{CH}_{4}\right.$, etc. $)$ are expressed as:

$X_{\mathrm{C}, i}=\frac{\text { mass of } C \text { in gas } i}{\text { mass of } C \text { in glucose }} \times 100$

$X_{\mathrm{H}, i}=\frac{\text { mass of } \mathrm{H} \text { in } \mathrm{H}_{2}}{\text { mass of } \mathrm{H} \text { in glucose }} \times 100$

\subsubsection{Liquid residue}

Glucose concentration was measured by HPLC DIONEX ICS-3000 with amperometric detector and $\mathrm{NaOH}$ eluant at constant flow rate. The column Carbopac PA 1 leads the quantification of glucose and 5-hydroxy methyl furfural at $35^{\circ} \mathrm{C}$.

The total organic and inorganic carbon in the liquid phase was measured with a TOC analyzer (Shimadzu TOC-5050).

\subsubsection{Solid residue}

Characterization of the generated solid phase has been performed by an environmental scanning electron microscope (ESEM, Philips XL30 FEG) in nitrogen atmosphere at ambient temperature. The EDS detector (energy dispersive spectroscopy) revealed the chemical composition of the surface, especially in the presence of alkali or metals.

Thermo Gravimetric Analysis of solid residues was performed under $\mathrm{N}_{2}$ at a heating rate of $5^{\circ} \mathrm{C} \mathrm{min}^{-1}$ from $30^{\circ} \mathrm{C}$ to $800^{\circ} \mathrm{C}$ using a TGA-DSC B111 SETARAM instrument. Solid samples $(15 \mathrm{mg})$ were heated on a platinum crucible.

\section{Results and discussion}

\subsection{Glucose decomposition during the heating phase}

Literature data pointed out that glucose concentration decreased rapidly during supercritical water gasification in continuous reactors $[14,19]$. Among the intermediates, 5-hydroxy methyl furfural (5-HMF) is one of the most reported [17,26,32]. An experiment ( $500 \mathrm{~mL}$ autoclave) has been dedicated to follow glucose and 5-HMF concentrations during the heating of a glucose solution ( $0.5 \mathrm{wt} \%$, without catalyst). The heating power was chosen at $50 \%$ of its maximum (heating rate lower than $20^{\circ} \mathrm{C} \mathrm{min}^{-1}$ ), and the liquid contained in the reactor was sampled every $10^{\circ} \mathrm{C}$. The temperature and pressure profiles obtained as a function of time are reported in Fig. 1. As a consequence of the physical and chemical processes developed in the system, although the delivered power was constant, the increase of the temperature of the reaction medium shows two distinct regions: $12^{\circ} \mathrm{C} \mathrm{min}-1$ between 20 and $180^{\circ} \mathrm{C}$, decreasing to $3^{\circ} \mathrm{C} \mathrm{min}^{-1}$ after the zone of abrupt change of slope observed between 180 and $250^{\circ} \mathrm{C}$.
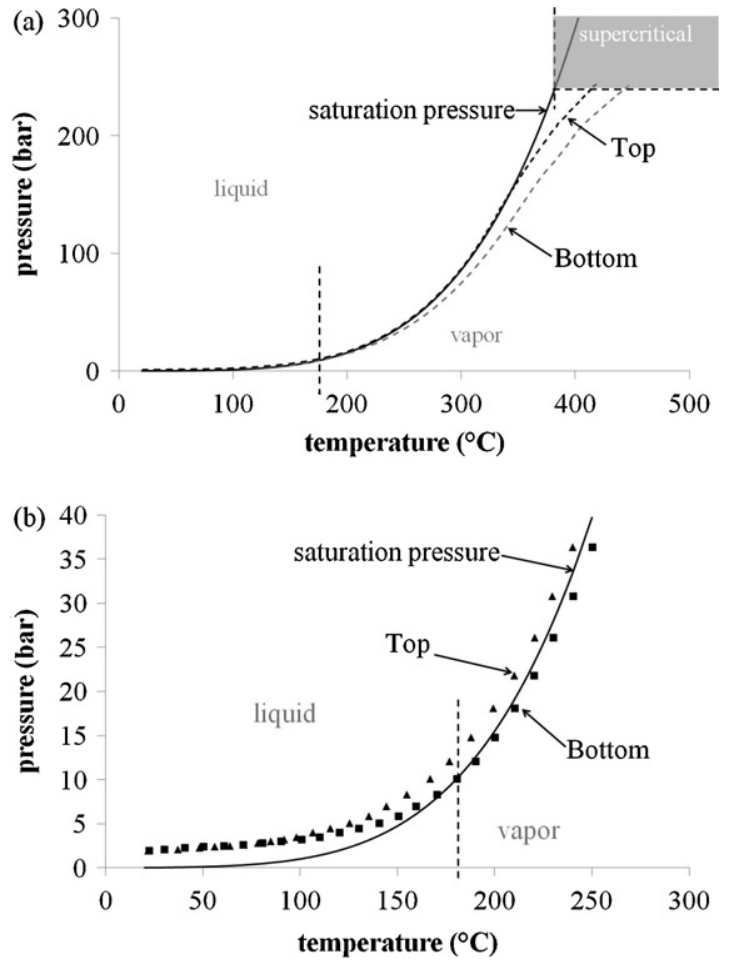

Fig. 2. Representation of the simulated curve of saturation pressure (solid line) during the heating of a glucose solution in the $500 \mathrm{~mL}$ batch reactor. The experimental $(T, P)$ couples measured in the reactor are also plotted. (a) Range of $20-450^{\circ} \mathrm{C}$, dotted line representing the temperature measured by the top and bottom thermocouples. (b) Range of $20-250^{\circ} \mathrm{C}$, symbols representing the temperature measured by the top and bottom thermocouples.

Simultaneously the pressure measured in the reactor increased almost continually from 2 to 36 bar.

In Fig. 2 we plotted the simulation results of the saturation pressure of an isochoric process of the solution containing $0.5 \mathrm{wt} \%$ of glucose (Peng-Robinson model, ASPEN, binary system) with the assumption of no conversion of glucose (constant concentration). Fig. 2(a) presents the curve of saturation pressure versus temperature until $374{ }^{\circ} \mathrm{C}$, and Fig. 2 (b) is a magnification of the region from 20 to $250^{\circ} \mathrm{C}$. The two dotted lines in Fig. 2(a) plot the experimental $(T, P)$ couples recorded in the reactor by the bottom and the top thermocouples and the measured pressure, respectively. Fig. 2(a) and (b) shows that the bottom region of the reactor contains liquid up to $180^{\circ} \mathrm{C}$, while the top temperature of the reactor places the system in vapor only around $350^{\circ} \mathrm{C}$, just before the critical temperature. According to the simulation results, the mass of liquid decreases by vaporization between 180 and $250^{\circ} \mathrm{C}$ (Fig. 2(b)). This process, occurring with energy uptake, is complete at $250^{\circ} \mathrm{C}$ and can explain the change of temperature dynamics observed experimentally between 180 and $250^{\circ} \mathrm{C}$. From $180^{\circ} \mathrm{C}$, the vapor/liquid media is placed on the saturation curve. According to the simulation results, glucose concentration in the vapor phase can be neglected, $10^{-3} \mathrm{wt} \%$ compared to the initial solution composition of $0.5 \mathrm{wt} \%$. These data confirm that sampling and analysis of the liquid phase can represent the glucose amount in the reactor.

However, glucose volume concentration in the liquid, a parameter of a kinetic law, may vary with the variation of solution density along the isochoric heating process. The volume and density of the solution were simulated by using NIST thermodynamic software for the experimental $(P, T)$ couples, and the water ionic product, $K_{w}$, was calculated by hand using the correlation proposed by Uematsu and Frank [33]. Both parameters are reported in Fig. 3. 


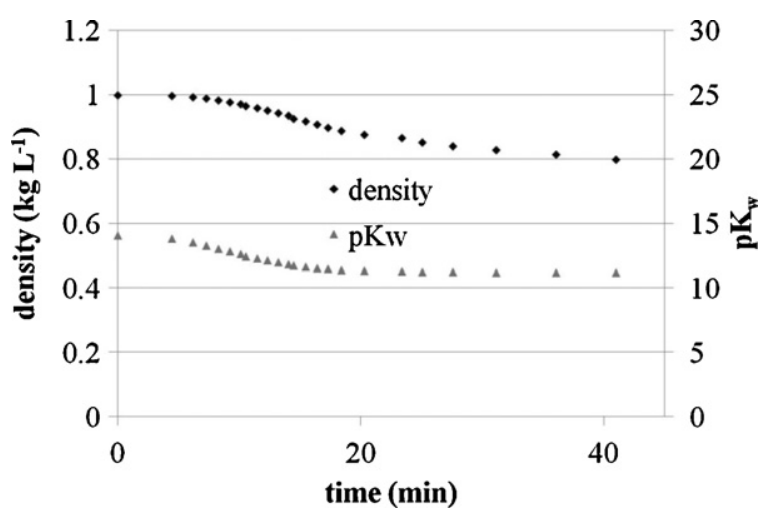

Fig. 3. Variation of density (calculated through experimental $T$ and $P$ ) and $\mathrm{pKw}$ of pure water versus time during the heating.

The simulation results of density and liquid volume allow calculating the volume concentration of glucose in the liquid phase of the reactor along the heating process using the experimental concentrations. Fig. 4 compares glucose experimental volume concentrations analyzed in normal $P, T$ conditions (dots TPNC) with the calculated ones for the system conditions $(T P)$ as a function of temperature (Fig. 4(a)) and time (Fig. 4(b)).

The decrease of water density [8] and dielectric constant [9] has important consequences on the solubilization properties of water [5,10]. The ionic product $K_{w}$ increases about $10^{3}$ times (about $10^{-11} \mathrm{M}^{2}$ ) at $200^{\circ} \mathrm{C}$ and 15 bars, favoring ionic reactions compared to radical reactions. As remarked in Fig. 4, until $180^{\circ} \mathrm{C}$ only $15 \%$ of the initial glucose amount was decomposed. Then glucose concentration decreased drastically, being completely degraded at
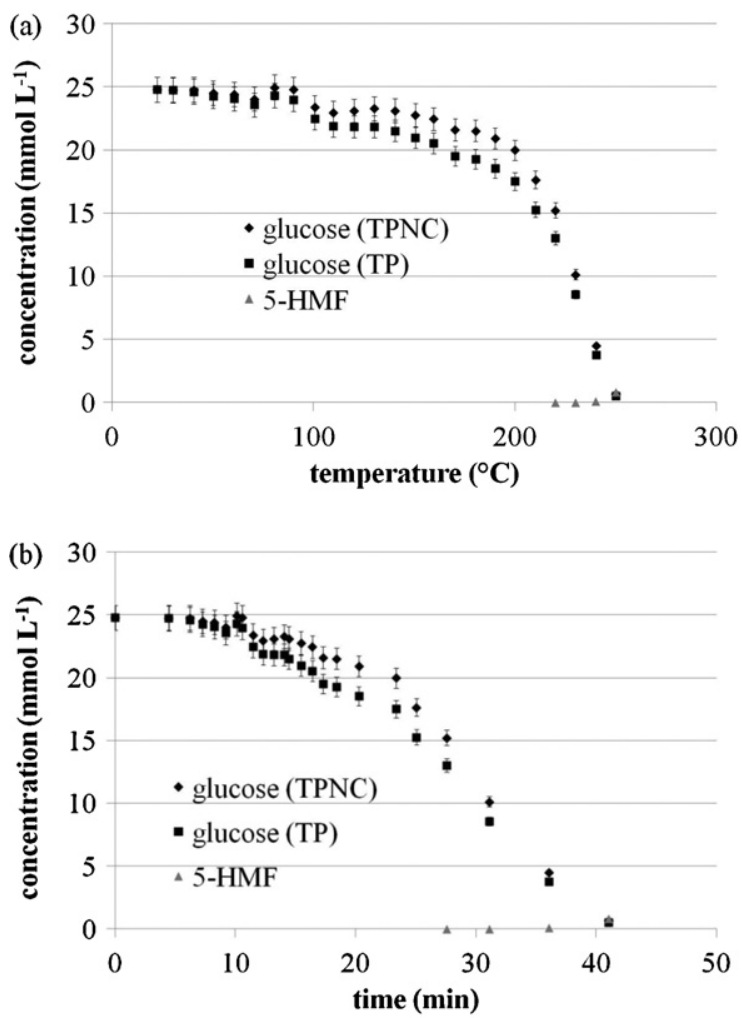

Fig. 4. Variation of glucose and 5-HMF concentration versus temperature (a) and time (b) during the heating of a glucose solution in the $500 \mathrm{~mL}$ batch autoclave. Solution contains $0.5 \mathrm{wt} \%$ of glucose and no catalyst. Glucose concentration was measured at normal conditions (TPNC) and then recalculated at conditions of the reactive media $(T P)$.

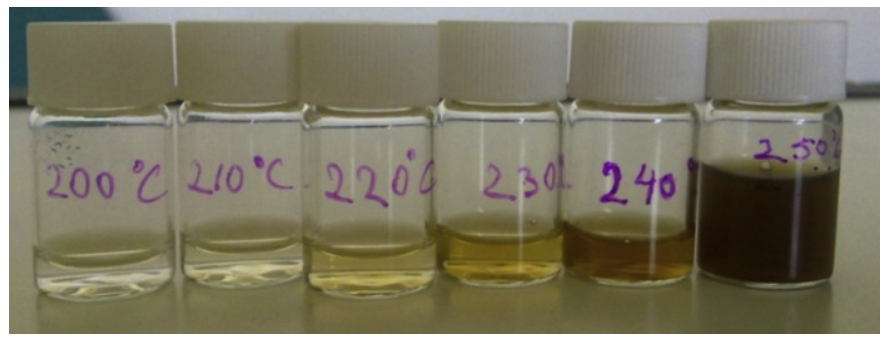

Fig. 5. Color variation of liquid sampled during the heating of a glucose solution. Solution contains $0.5 \mathrm{wt} \%$ of glucose and no catalyst.

$250^{\circ} \mathrm{C}$. Experimentally it was shown that glucose completely disappeared from the reaction medium when the supercritical state was reached. However higher heating rates, which can be achieved in continuous processes, produce less glucose degradation prior to reaching the supercritical domain.

5-HMF was only detected from temperatures over $220^{\circ} \mathrm{C}$ and reached $0.1 \mathrm{mg} \mathrm{L}^{-1}(0.83 \mathrm{mM})$ at $250^{\circ} \mathrm{C}$. The solution color was light yellow in the presence of 5-HMF. With temperature increase, the color of the solution changed from orange to deep brown, which can be attributed to 5-HMF polymerization or formation of phenolic compounds (Fig. 5). Fang et al. [34] followed in a diamond cell the concentrations of glucose and colored compounds at various heating rates (from 0.2 to $17^{\circ} \mathrm{C} \mathrm{s}^{-1}$ ). The authors reported glucose's total conversion at $300^{\circ} \mathrm{C}$ and $16.5 \mathrm{MPa}$, whatever the heating rate. 5 -HMF concentration increased at $220^{\circ} \mathrm{C}$, but it reacted rapidly producing polymeric by-products and coloring the solution in brown (5-HMF is the precursor of caramel).

In conclusion, it is difficult to propose a simple global mechanism for glucose conversion in supercritical water. As observed, depending on the heating rate, glucose could be more or less completely converted before reaching the supercritical domain of water, and the formed components can react by different pathways. The glucose decomposition mechanism is complex, particularly in the case of the batch process with a heating rate lower than $10^{\circ} \mathrm{C} \mathrm{min}^{-1}$.

\subsection{Influence of reaction temperature}

Experiments were carried out simultaneously in a series of 5 mini-autoclaves, processed with the same protocol and conditions. The solutions contained $5 \mathrm{wt} \%$ glucose and a catalyst $\left(\mathrm{K}_{2} \mathrm{CO}_{3}, 0.5 \mathrm{wt} \%\right)$, reaction time was kept constant at $60 \mathrm{~min}$ and the pressure at $25 \mathrm{MPa}$. The variable parameter was the conversion temperature, situated in a range from 400 to $600^{\circ} \mathrm{C}$.

\subsubsection{Gas composition}

Fig. 6 presents the conversion efficiency of the carbon and hydrogen contained in glucose into gases containing carbon (Eq. (1)) and into molecular hydrogen (Eq. (2)), respectively. These parameters take into account the total volume of gas produced and its composition. The main gases produced are $\mathrm{H}_{2}, \mathrm{CO}_{2}, \mathrm{CH}_{4}$ and $\mathrm{C}_{2} \mathrm{H}_{6}$.

Conversion efficiency of the different gases is in accordance with literature [14,35], increasing quasi linearly with the temperature. Higher yields for hydrogen can be observed at the highest temperatures, and generally high temperature favors glucose gasification. This behavior was observed experimentally and thermodynamically modeled [36], and it can be explained by water properties. Supercritical water improves radical reactions with temperature increase, therefore promoting gas production [37]. As observed, the carbon contained in glucose is preferentially converted into carbon dioxide than into light hydrocarbons such as methane. Moreover, the $\mathrm{CO}$ was not detected in the different gas phases. The alkaline 


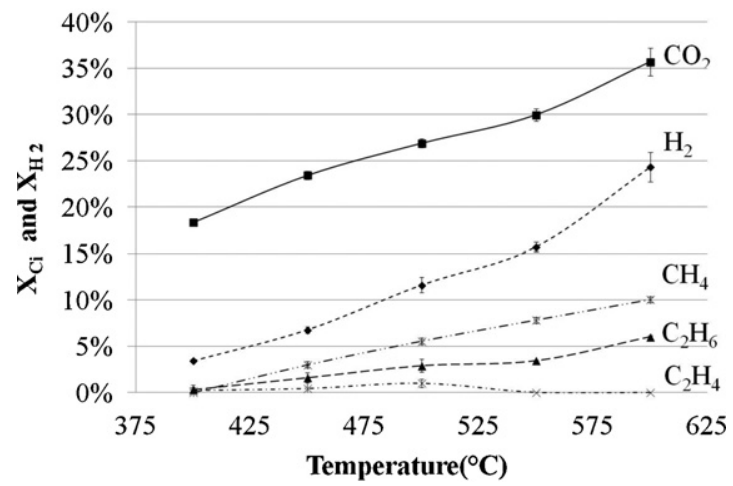

Fig. 6. Influence of temperature on the efficiency of carbon $\left(X_{i}\right)$ and hydrogen $\left(X_{\mathrm{H}_{2}}\right)$ conversion into gas for glucose solutions ( $5 \mathrm{wt} \%$ of glucose, $25 \mathrm{MPa}, 1 \mathrm{~h}$, $\left.\left[\mathrm{K}_{2} \mathrm{CO}_{3}\right]=0.5 \mathrm{wt} \%\right)$.

catalyst $\left(\mathrm{K}_{2} \mathrm{CO}_{3}\right)$ favors the water gas shift reaction by consuming $\mathrm{CO}$. The batch process (longer residence time in supercritical conditions) improves this behavior because $\mathrm{CO}$ was generally detected in the gas phase of continuous processes [14,17]. While carbon conversion into $\mathrm{C}_{2} \mathrm{H}_{6}$ increases with temperature, $\mathrm{C}_{2} \mathrm{H}_{4}$ is only produced at low temperatures $\left(400-500^{\circ} \mathrm{C}\right)$ and then disappears in the gas phase above $550^{\circ} \mathrm{C}$. Ethylene is a result of radical dehydrogenation of hydrocarbons. The ethylene content of the gas phase, quantified even at long reaction time $(60 \mathrm{~min})$, suggests that $\mathrm{C}_{2} \mathrm{H}_{4}$ is not only produced in the early reaction period. The decrease of ethylene production can be correlated with its higher reactivity at higher temperature. Dybkjaer [38] showed that the ethylene polymerization can be obtained at $600^{\circ} \mathrm{C}$ following this mechanism: $\mathrm{C}_{2} \mathrm{H}_{4} \rightarrow$ olefins $\rightarrow$ polymers $\rightarrow$ coke.

The molar conversion into $\mathrm{H}_{2}$ is increasing from 0.3 to $1.5 \mathrm{~mol}$ $\mathrm{H}_{2}$ per mol glucose, which is largely less than the maximum theoretical value ( $12 \mathrm{~mol} \mathrm{H}_{2}$ per mol glucose). This low conversion is partially explained by the generation of light hydrocarbons containing hydrogen atoms. Molecular hydrogen production efficiency is largely higher with continuous gasification of glucose solutions in supercritical water conditions [36]. As shown in the first part of this work, glucose molecules are supposed to be totally converted when the reaction temperature is reached. During heating, different reactions on glucose can occur by generating smaller molecules but also bigger, by more or less developed polymerization. It can be supposed that these last molecules are more stable, limiting therefore hydrogen generation in the process. Moreover, reduced reaction times, up to $60 \mathrm{~min}$, influence the gasification yields by stabilizing hydrogen production and increasing the amount of $\mathrm{CO}_{2}$ produced [31]. The reaction time in batch reactors did not necessarily increase the hydrogen production. Combining the amount of each gas and their lower calorific values (LCV), the global LCV of the gaseous products varies from 17 to $260 \mathrm{kcal}$ per mol of glucose for reaction temperatures from 400 to $600^{\circ} \mathrm{C}$.

\subsubsection{Analysis of carbon in liquid state}

Total organic carbon (TOC) and total inorganic carbon (IC) were quantified in the liquid phase, and the evolution is represented in Fig. 7. The initial TOC and IC values of the glucose solution containing the catalyst are respectively $22.2 \mathrm{~g} \mathrm{~L}^{-1}$ and $564.3 \mathrm{mg} \mathrm{L}^{-1}$. The IC values reported in Fig. 7 do not contain the contribution of the initial amount of catalyst $\left(\mathrm{K}_{2} \mathrm{CO}_{3}\right)$. TOC of the solution decreases when temperature increases, corresponding to an enhancement in gas production, as presented in Fig. 6 . The consumption of the organic carbon seems to be non-linear in the temperature domain studied. A sharper decrease appears until $500^{\circ} \mathrm{C}$, but this phenomenon is not correlated with an increase in gas production (Fig. 6). The increase of temperature acts on the kinetics of the reactions involved in

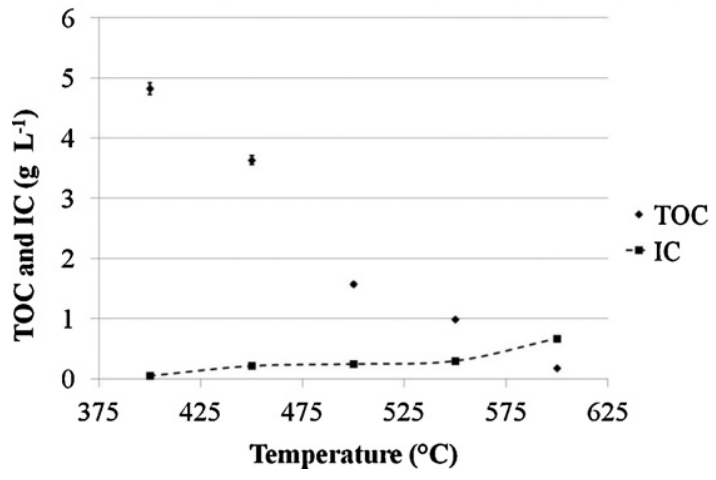

Fig. 7. Influence of temperature on the TOC and IC values of the liquid phase for glucose solutions ( $5 \mathrm{wt} \%$ of glucose, $25 \mathrm{MPa}, 1 \mathrm{~h},\left[\mathrm{~K}_{2} \mathrm{CO}_{3}\right]=0.5 \mathrm{wt} \%$ ).

the process, but the effect depends on their activation energy (e.g., Arrhenius law). All the reactions should be considered to explain the profile of the curve.

Total organic carbon (TOC) is an interesting global parameter that supports the reaction evolution in the liquid phase. In fact, a high TOC decrease results from gasification or carbonization, while a light decrease is attributed to liquefaction. As reported in the literature, high temperature $\left(>500^{\circ} \mathrm{C}\right)$ promotes gasification while liquefaction is improved at lower temperatures $[5,17]$. In our experiments, the organic carbon conversion is already efficient: at $400^{\circ} \mathrm{C}$ its removal is $78 \%$ while it is quasi totally removed from the liquid phase at $600^{\circ} \mathrm{C}$ after $1 \mathrm{~h}$ treatment. The main part of organic compounds (glucose and intermediates) has been degraded under these conditions and transferred to gas or solid phases.

IC values slightly increase with temperature which implies an increase in carbonates concentration. By increasing the temperature, the partial pressure of $\mathrm{CO}_{2}$ increases, and the alkaline $\mathrm{pH}$ of the residual solution favor carbonate uptake.

To close the carbon balance of the process it is necessary to characterize the solid phase also formed in the reactor. While the mass of solid could not be appropriately weighed because it was sticking to the reactor walls, only the solid surface and thermal characterization were realized. As an example at $600^{\circ} \mathrm{C}$, the mass of solid residue represents $8 \%$ of the glucose initial mass, and taking into account the solid composition, $17 \%$ of the carbon was recovered in the solid phase. The global carbon balance in this case reached only $72 \%$.

\subsection{Analysis of solid residues: effect of process parameters}

Hydrothermal carbonization of biomass (saccharides, cellulose, lignocellulose, starch, etc.) became an interesting research subject trying to reproduce the natural bio-geological process in laboratory and pilot conditions [39-43]. The objective is to synthesize a rich carbonaceous solid for energy storage (high C content) and/or composed from particles with designed microstructure and properties. Sevilla and Fuertes [40] performed hydrothermal carbonization of glucose in batch processes under different conditions: temperature range from $170^{\circ} \mathrm{C}$ to $240^{\circ} \mathrm{C}$, reaction time from 0.5 to $15 \mathrm{~h}$, concentrations from 0.1 to $1 \mathrm{~mol} \mathrm{~L}^{-1}$ under auto-generated pressure. They obtained a solid, also called hydrochar, composed of spherical carbonaceous particles with a high degree of uniformity in their diameter distribution $(0.4-6 \mu \mathrm{m})$, correlated with the synthesis conditions. They proposed a multistep formation mechanism for the microspheres: dehydratation/fragmentation of glucose molecules leading to soluble products (furfurals, HMF, carboxylic acids, etc.). Titirici et al. [42] proposed a parallel mechanism based on the formation of furans rings in the first earlier phase of carbonization. In the conditions of the process these compounds 


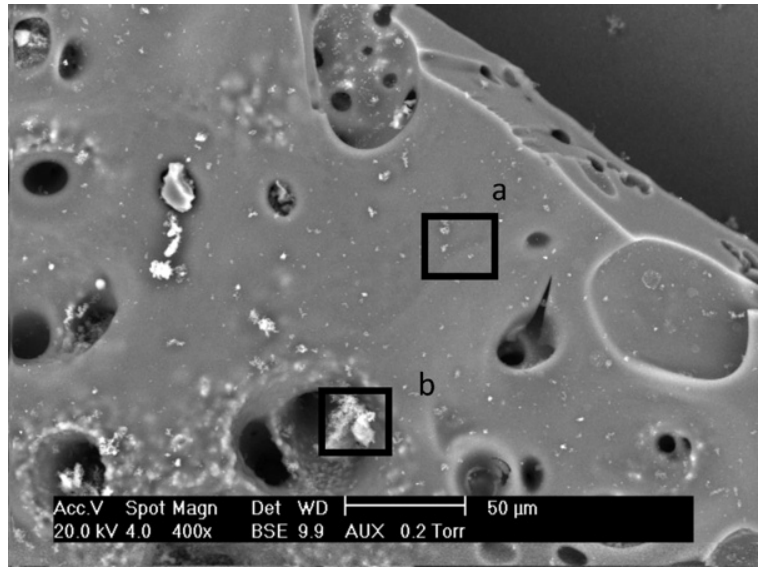

Fig. 8. ESEM images of solid residue from the SCWG of glucose solutions. Operating conditions: 5 wt $\%$ glucose, $450{ }^{\circ} \mathrm{C}, 25 \mathrm{MPa}, 1 \mathrm{~h}$, batch reactor of $500 \mathrm{~mL}$.

react together (condensation, polymerization) forming bigger soluble molecules, stabilized by aromatization. When the concentration of these molecules exceeds the critical supersaturation point, burst nucleation occurs [44] followed by diffusional growth. The generated nuclei are subject to a surface growth by a diffusional process forming the microspheres. A polymerization mechanism to form carbon particles was also suggested [43].

Our reported experiments have been conducted for lower reaction times under high temperatures and pressures, in the supercritical domain of water, favoring gasification. The cooling rate of the $500 \mathrm{~mL}$ stirred autoclave was lower $\left(10^{\circ} \mathrm{C} \mathrm{min}^{-1}\right)$ compared to the $5 \mathrm{~mL}$ autoclaves $\left(25^{\circ} \mathrm{C} \mathrm{min}^{-1}\right)$ while the homogenization of the medium was better by stirring.

Therefore some of the characteristics of the obtained solids are less homogeneous. Solid residues obtained in various experiments were observed by environmental scanning electron microscopy (ESEM), those shown in Figs. 8 and 9 were obtained by batch gasification at $450^{\circ} \mathrm{C}$ and $25 \mathrm{MPa}$ during $60 \mathrm{~min}$ reaction times, without catalyst. Fig. 8 illustrates the general morphology of the solid residues obtained by the supercritical water gasification of glucose solution ( $5 \mathrm{wt} \%$ ), which is independent of the operating conditions. These magnifications reveal rough and smooth parts (phases) contained in the sampled solid. The same morphology of solid is obtained with or without catalyst and is consequently not due to the alkaline content of the medium, but can be linked, probably, to different local conditions during the process, i.e., contact with the reactor surface, heterogeneities in composition, cooling procedure, etc. The composition of the two zones ( $a$ and b, Fig. 8) determined by EDS are similar: $92-93$ wt\% carbon and $7-8$ wt\% oxygen, testifying of high carbon content obtained mainly by quantitative
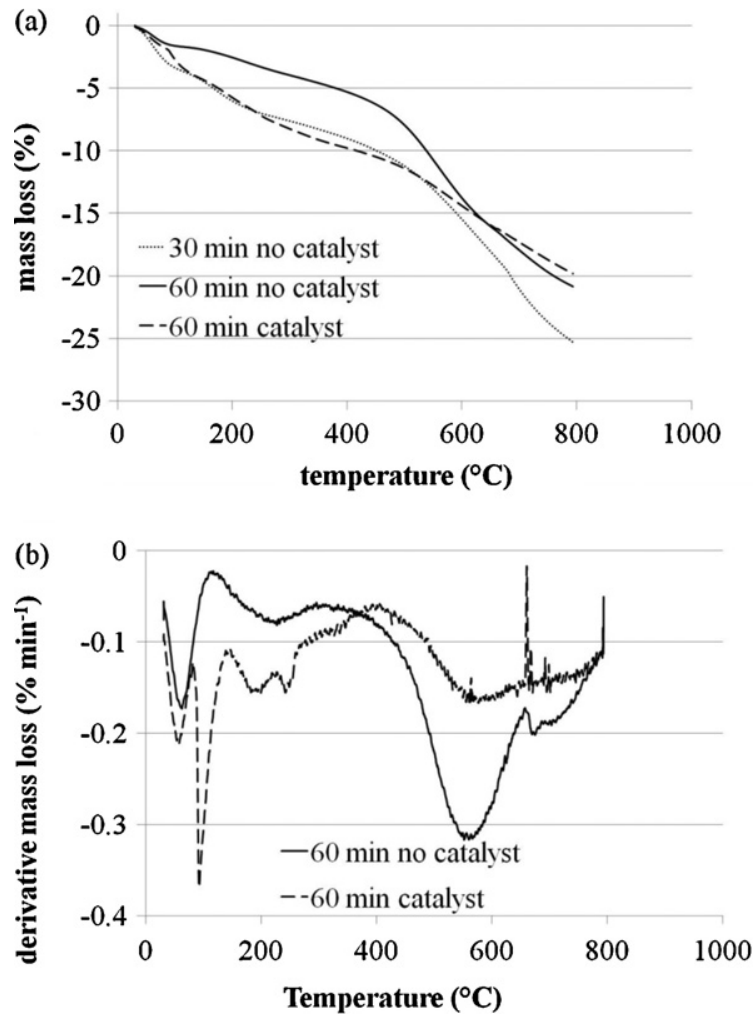

Fig. 10. Mass loss (a) and derivative mass loss (b) of solid residues versus temperature in TGA instrument. Solids from SCWG of $5 \mathrm{wt} \%$ glucose solution, with or without catalyst at various reaction times $\left(450^{\circ} \mathrm{C}, 25 \mathrm{MPa}, 5 \mathrm{~mL}\right.$ autoclaves $)$.

dehydration. The solid has a composition close to coke, and the structure, investigated by X-ray diffraction is amorphous.

An enlargement of both zones is presented in Fig. 9. The surface seems to be apparently smooth (Fig. 9(a)) with this magnification, while the roughness increases for the second zone (Fig. 9(b)), corresponding probably to a phase inversion during cooling. The roughness is due to agglomerates of small pockets whose diameter is typically $0.5 \mu \mathrm{m}$. However, some isolated particles reached $2 \mu \mathrm{m}$ diameters (not shown). All the obtained solids present the same characteristics of morphology of surface and sphericity of the carbon particles. The different tested conversion conditions have limited influence on the structure of the carbonaceous solid.

The thermo-gravimetric analysis (TGA, heating rate: $5^{\circ} \mathrm{C} \mathrm{min}^{-1}$ ) of the solids reveals different behaviors correlated with the presence of catalyst in the solution and reaction time but not to the type of autoclave. Fig. 10 compares TGA results for the carbonaceous solids obtained at $60 \mathrm{~min}$ reaction time with and without the presence of catalyst and a solid obtained at $30 \mathrm{~min}$ reaction time

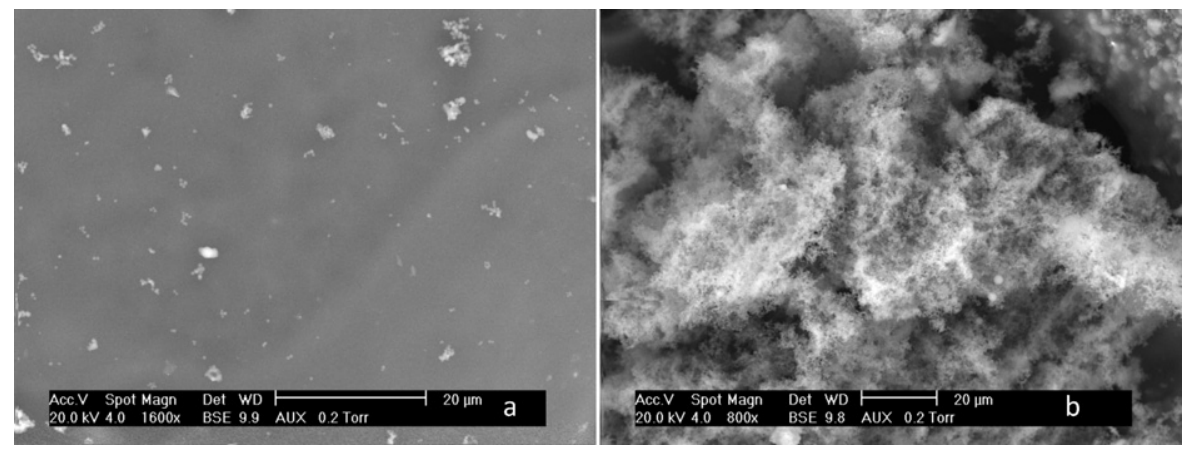

Fig. 9. ESEM images of solid residue from the SCWG of glucose solutions. Enlargement of both a and b zones from Fig. 6 . 
in the absence of catalyst. Temperature and pressure are the same for all the compared experiments. $\mathrm{K}_{2} \mathrm{CO}_{3}$ and $\mathrm{KOH}$, supposed to be formed during the water gas shift pathway according to Sinag et al. [17], are stable up to $800^{\circ} \mathrm{C}$ : they do not interfere with the organic mass loss.

Qualitatively, three main zones can be observed in TGA results, Fig. 10 (a). Until $100^{\circ} \mathrm{C}$, mass losses occur with different rates for the three compared solids. In this temperature range, mass loss may be linked to water evaporation and degassing of (highly) volatile compounds. The process dynamics may be favored by a more porous structure. The mass loss is the lowest for the solid obtained during a reaction time of $1 \mathrm{~h}$ in the absence of catalyst. However the solid obtained with catalyst during a reaction time of $1 \mathrm{~h}$ and the one obtained without catalyst in 30 min have a similar mass loss.

A second zone can be observed at around $600^{\circ} \mathrm{C}$. Solids obtained by catalytic conversion during $1 \mathrm{~h}$ and by non-catalytic conversion during $30 \mathrm{~min}$ have very similar behavior, characterized by an almost constant mass loss rate. On the contrary, the solid obtained by catalytic conversion during $1 \mathrm{~h}$ shows a better stability until $500{ }^{\circ} \mathrm{C}$ followed by a net acceleration of mass loss in the interval $500-600^{\circ} \mathrm{C}$.

Below $150^{\circ} \mathrm{C}$, mass loss seems to be composed by two distinct processes, revealed by derivative analysis (Fig. 10(b)). This phenomenon can be explained by the catalyst presence as reported by Meljac et al. [45]. The authors observed the decomposition of $\mathrm{KHCO}_{3}$ between 120 and $158^{\circ} \mathrm{C}$ (depending on the heating rate) $\mathrm{K}_{2} \mathrm{CO}_{3}$ is added to the solution, contributing to the acid/base equilibrium of the system and the $\mathrm{KHCO}_{3}$ can be formed.

Until $500^{\circ} \mathrm{C}$ the solid obtained by $1 \mathrm{~h}$ non-catalytic conversion has better thermal stability. The alkaline catalyst was added to promote the water gas shift reaction and, more generally, gasification. Gasification is favored by formation of smaller molecules which are thermally less stable. The contribution of catalyst in the conversion process may explain the behavioral difference between the two solids in this temperature range. At $600^{\circ} \mathrm{C}$ the mass loss of all solids is close, about $14 \%$ for catalytic conversion and about $15 \%$ for the non-catalytic conversion.

The last zone $\left(600-800^{\circ} \mathrm{C}\right)$ reveals the contribution of the reaction time to the thermal stability of the solids. The carbonaceous solid obtained after $30 \mathrm{~min}$ reaction time is less stable, its mass loss reaches $25 \%$, in contrast to the other two processes, with a mass loss of approximately $20 \%$. We can correlate this behavior to the progress of the aromatization mechanism presented above: a longer reaction time may be necessary to achieve a more compact aromatic structure of the solid (closer to graphite).

\section{Conclusion}

The goal of our work was to study the glucose degradation during heating and the effect of process parameters on the supercritical water gasification of glucose solutions through the characterization of the three phases formed. This paper presents only the influence of the temperature, which was determined as one of the main influencing parameters. Batch processing results in a higher heating time than in continuous processes, and as a consequence, we observed the degradation of glucose at low temperature and in a relatively short time. $250{ }^{\circ} \mathrm{C}$ was reached in $40 \mathrm{~min}$ in our $500 \mathrm{~mL}$ autoclave, and glucose was quantitatively degraded in the liquid phase producing e.g., 5-hydroxy methyl furfural. The colorless solution changes to a deep brown color, characteristic of caramel polymerization. In autoclaves, glucose reacts totally before reaching the critical point of water using slow heating rates (below $\left.10^{\circ} \mathrm{C} \mathrm{min}^{-1}\right)$.
SCWG of glucose solutions, and particularly hydrogen production, was favored at high temperature with efficiency of $1.5 \mathrm{~mol} \mathrm{H}_{2}$ per mol glucose at $600{ }^{\circ} \mathrm{C} \mathrm{(5} \mathrm{wt \%} \mathrm{glucose,} 0.5 \mathrm{wt} \%$ catalyst, $25 \mathrm{MPa}$, $60 \mathrm{~min}$ ). This yield is lower than the maximal theoretical value and can be explained by the competitive conversion of organic matter to solid and liquid phase. The TOC is increasingly removed from the solution with the temperature. The production of valuable platform molecules such as 5-HMF requires subcritical temperatures while energetic valorization as hydrogen is obtained in the supercritical domain. The amorphous solid residues are mainly composed of rough and smooth surfaces. The roughness was due to carbon particles whose spherical morphology seemed to be affected by the heating and cooling rates. On the contrary, the catalyst and the reaction time affect the organic content of the solid, highlighted by thermochemical analysis. In fact, the organics in the solid phase are less sensitive to heat if generated by catalytic processes at lower reaction times.

\section{Acknowledgments}

The authors want to thank Christine Rolland for ESEM pictures and Celine Boachon for TGA analyses.

\section{References}

[1] DIRECTIVE 2009/28/EC of the European Parliament and of the Council of 23 April 2009.

[2] A. Demirbas, Biorefineries: current activities and future developments, Energy Conversion and Management 50 (2009) 2782-2801.

[3] G. Brunner, Near critical and supercritical water. Part I. Hydrolytic and hydrothermal processes, J. Supercritical Fluids 47 (2009) 373-381.

[4] A. Kruse, Hydrothermal biomass gasification, J. Supercritical Fluids 47 (2009) 391-399.

[5] A. Kruse, E. Dinjus, Hot compressed water as reaction medium and reactant. Properties and synthesis reactions, J. Supercritical Fluids 39 (2007) 362-380.

[6] A.A. Clifford, Reactions in supercritical water, Chimica Oggi 11 (1993) 36-37.

[7] R.W. Shaw, T.B. Brill, A.A. Clifford, C.A. Eckert, E.U. Franck, Supercritical water - a medium for chemistry, Chemical and Engineering News 69 (1991) 26-39.

[8] P.E. Savage, S.G. Gopalan, T.I. Mizan, C.J. Martino, E.E. Brock, Reactions at supercritical conditions: applications and fundamentals, AIChE 41 (1995) 1723-1778.

[9] W.L. Marshall, E.U. Franck, Ion product of water substance, $0-1000^{\circ} \mathrm{C}$, 1-10,000 bar new international formulation and its background, J. Physical and Chemical Reference Data 10 (1981) 295-304.

[10] J.W. Tester, A. Marrone, M.M. DiPippo, K. Sako, M.T. Reagan, T. Arias, W.A. Peters, Chemical reactions and phase equilibria of model halocarbons and salts in suband supercritical water (200-300 bar, $\left.100-600^{\circ} \mathrm{C}\right)$, J. Supercritical Fluids 13 (1998) 225-240

[11] S.E. Hunter, P.E. Savage, Recent advances in acid- and base-catalyzed organic synthesis in high-temperature liquid water, Chemical Engineering Science $22 / 23$ (2004) 4903-4909.

[12] A. Kruse, E. Dinjus, Hot compressed water as reaction medium and reactant. 2 Degradation reactions, J Supercritical Fluids 41 (2007) 361-379.

[13] Y. Matsumura, T. Minowa, B. Potic, S.R.A. Kersten, W. Prins, W.P.M. van Swaaij, B. van de Beld, D.C. Elliott, G.G. Neuenschwander, A. Kruse, M.J. Antal, Biomass gasification in near- and super-critical water: status and prospects, Biomass and Bioenergy 29 (2005) 269-292 (review).

[14] I.G. Lee, M.S. Kim, S.K. Ihm, Gasification of glucose in supercritical water, Industrial and Engineering Chemistry Research 41 (2002) 1182-1188.

[15] M. Watanabe, H. Inomata, K. Arai, Catalytic hydrogen generation from biomass (glucose and cellulose) with $\mathrm{ZrO}_{2}$ in supercritical water, Biomass and Bioenergy 22 (2002) 405-410.

[16] T.M. Aida, Y. Sato, M. Watanabe, K. Tajima, T. Nonaka, H. Hattori, K. Arai, Dehydration of D-glucose in high temperature water at pressures up to $80 \mathrm{MPa}$, J. Supercritical Fluids 40 (2007) 381-388.

[17] A. Sinağ, A. Kruse, V. Schwarzkopf, Key compounds of the hydropyrolysis of glucose in supercritical water in the presence of $\mathrm{K}_{2} \mathrm{CO}_{3}$, Industrial and Engineering Chemistry Research 42 (2003) 3516-3521.

[18] A.K. Goodwin, G.L. Rorrer, Conversion of glucose to hydrogen-rich gas by supercritical water in a microchannel reactor, Industrial and Engineering Chemistry Research 47 (2008) 4106-4114.

[19] E. Weiss-Hortala, A. Kruse, C. Ceccarelli, R. Barna, Influence of phenol on glucose degradation during supercritical water gasification, J. Supercritical Fluids 53 (2010) 42-47.

[20] A. Kruse, A. Krupka, V. Schwarzkopf, C. Gamard, T. Henningsen, Influence of proteins on the hydrothermal gasification and liquefaction of biomass. 1. Comparison of different feedstocks, Industrial and Engineering Chemistry Research 44 (2005) 3013-3020. 
[21] B. Girisuta, L.P.B. Janssen, H.J. Heeres, A kinetic study on the conversion of glucose to levulinic acid, Chemical Engineering Research and Design 84 (2006) 339-349.

[22] M. Sasaki, G. Sekiguchi, T. Adschiri, K. Arai, Rapid and selective conversion of cellulose to valuable chemical intermediates with supercritical water, in: Proceeding 6th International Symposium on Supercritical Fluids, 2003.

[23] B.M. Kabyemela, T. Adschiri, R.M. Malaluan, K. Arai, Glucose and fructose decomposition in subcritical and supercritical water: detailed reaction pathway, mechanisms and kinetics, Industrial and Engineering Chemistry Research 38 (1999) 2888-2895.

[24] Z. Srokol, A.-G. Bouche, A. van Estrik, R.C.J. Strik, T. Maschmeyer, J.A. Peters, Hydrothermal upgrading of biomass to biofuel; studies on some monosaccharide model compounds, Carbohydrate Research 339 (2004) 1717-1726.

[25] A. Onda, T. Ochi, K. Kajiyoshi, K. Yanagisawa, A new chemical process for catalytic conversion of D-glucose into lactic acid and gluconic acid, Applied Catalysis A: General 343 (2008) 49-54.

[26] D. Klingler, H. Vogel, Influence of process parameters on the hydrothermal decomposition and oxidation of glucose in sub- and supercritical water, J. Supercritical Fluids 55 (2010) 259-270.

[27] D. Sutton, B. Kelleher, J.R.H. Ross, Review of literature on catalysts for biomass gasification, Fuel Processing Technology 73 (2001) 155-173.

[28] J. Yanik, S. Ebale, A. Kruse, M. Saglam, M. Yüksel, Biomass gasification in supercritical water: II. Effect of catalyst, International J. Hydrogen Energy 33 (2008) 4520-4526.

[29] D.C. Elliott, Review Catalytic hydrothermal gasification of biomass, Biofuels Bioproducts and Biorefining 2 (2008) 254-265.

[30] Q.M. Yu-Wu, E. Weiss-Hortala, R. Barna, H. Boucard, S. Bulza, Glycerol and bioglycerol conversion in supercritical water for hydrogen production, Environmental Technology 33 (2012) 2245-2255.

[31] Q. Yu-Wu, Study of Biomass Conversion in Supercritical Water Processes to Produce Hydrogen: Application to Glucose, Glycerol and Bio-glycerol, PhD thesis, Toulouse University, 2012, p. 286

[32] A. Kruse, A. Gawlik, Biomass conversion in water at $330-410{ }^{\circ} \mathrm{C}$ and $30-50 \mathrm{MPa}$ Identification of key compounds for indicating different chemical reaction pathways, Industrial and Engineering Chemistry Research 42 (2003) 267-279.
[33] M. Uematsu, E.U. Frank, Static dielectric constant of water and steam, J. Physical and Chemical Reference Data 9 (1980) 1291-1306.

[34] Z. Fang, R.L. Smith Jr., J.A. Kozinski, T. Minowa, K. Arai, Reaction of D-glucose in water at high temperature $\left(410^{\circ} \mathrm{C}\right)$ and pressures $(180 \mathrm{MPa})$ for the production of dyes and nano-particles, J. Supercritical Fluids 56 (2011) 41-47.

[35] A. Sinağ, A. Kruse, J. Rathert, Influence in the heating rate and the type of catalyst on the formation of key intermediates and on the generation of gases during hydropyrolysis of glucose in supercritical water in a batch reactor, Industrial and Engineering Chemistry Research 43 (2004) 502-508.

[36] Y. Lu, L. Guo, X. Zhang, Q. Yan, Thermodynamic modeling and analysis of biomass gasification for hydrogen production in supercritical water, Chemical Engineering J. 131 (2007) 233-244.

[37] W. Bühler, E. Dinjus, H.J. Ederer, A. Kruse, C. Mas, Ionic reactions and pyrolysis of glycerol as competing reaction pathway in near- and supercritical water, J. Supercritical Fluids 22 (2002) 37-53.

[38] I. Dybkjaer, Tubular reforming and autothermal reforming of natural gas - an overview of available processes, Fuel Processing Technology 42 (1995) 85-107.

[39] M. Sevilla, A. Fuertes, Chemical and structural properties of carbonaceous products obtained by hydrothermal carbonization of saccharides, Chemistry A European J. 15 (2009) 4195-4203.

[40] M. Sevilla, A. Fuertes, The production of carbon materials by hydrothermal carbonization of cellulose, Carbon 47 (2009) 2281-2289.

[41] E. Dinjus, A. Kruse, N. Tröger, Hydrothermal carbonization - 1. Influence of lignin in lignocelluloses, Chemical Engineering Technology 34 (2011) 2037-2043.

[42] M. Titirici, R. White, M. Falco, M. Sevilla, Black perspectives for a green future: hydrothermal carbons for environment protection and energy storage, Energy and Environmental Science 5 (2012) 6796-6822.

[43] T. Karayildirim, A. Sinağ, A. Kruse, Char and coke formation as unwanted side reaction of the hydrothermal biomass gasification, Chemical Engineering Technology 31 (2008) 1561-1568.

[44] V.K. La Mer, Nucleation in phase transition, Industrial and Engineering Chemistry 44 (1952) 1270-1276.

[45] L. Meljac, L. Perier-Camby, G. Thomas, Calorimetric study of reactions occurring between impregnated activated fibres and hydrogen sulphide, Carbon 43 (2005) 1407-1415. 